\title{
'It's the Organization that Is Wrong' Exploring Disengagement from Organizations through Leadership Development
}

\author{
Larsson, Magnus; Holmberg, Robert; Kempster, Steve
}

Document Version

Accepted author manuscript

Published in:

Leadership

DOI:

$10.1177 / 1742715019879306$

Publication date:

2020

License

Unspecified

Citation for published version (APA):

Larsson, M., Holmberg, R., \& Kempster, S. (2020). 'It's the Organization that Is Wrong': Exploring

Disengagement from Organizations through Leadership Development. Leadership, 16(2), 141-162.

https://doi.org/10.1177/1742715019879306

Link to publication in CBS Research Portal

\section{General rights}

Copyright and moral rights for the publications made accessible in the public portal are retained by the authors and/or other copyright owners and it is a condition of accessing publications that users recognise and abide by the legal requirements associated with these rights.

Take down policy

If you believe that this document breaches copyright please contact us (research.lib@cbs.dk) providing details, and we will remove access to the work immediately and investigate your claim. 


\section{'It's the Organization that Is Wrong': Exploring Disengagement from Organizations through Leadership Development}

\section{Magnus Larsson, Robert Holmberg, and Steve Kempster}

Journal article (Accepted manuscript*)

\section{Please cite this article as:}

Larsson, M., Holmberg, R., \& Kempster, S. (२०२०). 'It's the Organization that Is Wrong': Exploring Disengagement from Organizations through Leadership Development. Leadership, 16(2), 141-162. https://doi.org/10.1177/1742715019879306

\section{DOl: https://doi.org/10.1177/1742715019879306}

Copyright (ㅇ The Author(s) २०19. Reprinted by permission of SAGE Publications.

\footnotetext{
* This version of the article has been accepted for publication and undergone full peer review but has not been through the copyediting, typesetting, pagination and proofreading process, which may lead to differences between this version and the publisher's final version AKA Version of Record.
} 


\title{
$\underline{\text { leadership development }}$
}

\begin{abstract}
This research explores the relationship between participation in leadership development programs and disengagement from the employing organization. Based on repeated interviews with 10 managers participating in an open leadership development program our analysis shows that half of the participants reflected a sense of distancing themselves from how their organizations practiced leadership and for some an emotional disengagement with their home organization which we see as analogous to changes in social identity. We problematize the role of management and leadership development programmes with regard to the relationship between organizations and employees. A series of paradoxes are reflected in our critique of this relationship. The most prominent in terms of implications is that a successful management and leadership development program - recognized by employees and employers - can generate dissatisfaction with the home organization as a consequence of the purpose of the program: to increase confidence and enhanced agency. This paradox has significant implication to the leadership development industry and we explore these implications.
\end{abstract}

Key Words: leadership development program; dissatisfaction; disengagement; managerial practices; agency

\section{'I don't want to remain here, and that is the fault of the program'}

How might we understand leadership development when, rather than resulting in increased engagement with organizational challenges, it results in participants distancing themselves, even to the point of considering leaving the organization? How can we understand learning processes that 
simultaneously increase self-confidence as leaders and limit engagement with organizational challenges? These sets of questions shape the orientation of this article.

The investment in the leadership development industry is enormous. Myatt (2012) estimated that globally approximately $\$ 170$ billion was spent annually on activities associated with leadership development. Whatever the estimate leadership development is a large industry, and the return on that investment can be anticipated to be associated with perhaps the following: a greater skill in leading, alignment to organizational ethos and values and greater commitment to the organization. Yet management and leadership development programs (MLDP's) create unexpected outcomes. The shadow side of MLDPs is rarely explored (Gilani, Bolden and Pye, 2016) with a dearth of attention and research to examining undesired outcomes of MLDPs (of the few examinations see Carroll and Nicholson, 2014; Gagnon, 2008; Gagnon and Collinson, 2014; Nicholson and Carroll, 2013). Our contribution is to explore the unintended consequences of an MLDP with regard to delegate disengagement with their employing organization. When we speak here of MLDP's we follow McGurk (2010) and Bolden (2016) in giving emphasis to programs with longer duration and that encompass a broad range of aspects, rather than leadership programmes that may be predominately focus on intra- and inter-personal orientations - for example the discovery of the authentic leader within. The breadth within MLDPs typically include a range of topics, such as change management, strategy formulation and translation, team dynamics, as well as interpersonal leadership skills. We outline further on the MLDP that our research draws that reflects these aspects.

The first and second authors, Magnus and Robert, were appointed to evaluate an MLDP hereafter known as 'LEADING'. We shall provide detail of the program further on but wish to point here to the remit of the evaluation. This was to evaluate the effects of the program in terms of the participating manager's well-being and ability to be effective in their role. The research highlighted positive outcomes in that participants, in comparison to a control group, reported improved wellbeing, an increase in leadership self-efficacy and enhanced political skills (Holmberg, Larsson \& 
Bäckström, 2016). There were also prominent unintended or shadow issues, most prominently the emotional distancing of some participants from their home organizations.

Our experiences of working on MLDP's over many years in a variety of contexts points to an axiomatic sense of expectancy of generating disruption and disengagement. In related work, Smith and Kempster (2019) has highlighted the prominence of a divorce per cohort with an MLDP working with owner-managers. Of the few examinations of disengagement within leadership development Carroll and Nicholson (2014) have helpfully highlighted that programs like this as sites of potential resistance. Rather than the resistance being against the program or facilitators Carroll and Nicholson highlight how resistance may become manifest through an awakening of the 'enslaved selves who follow organizational ideologies and scripts' (2014: 1418). In related research Nicholson and Carroll (2013) comment that '[R]ather than leadership development being a site that soothes existential distress, repairs damaged identities, and protects individuals from disturbances it may spark the opposite' (2013: 1226). It is to the 'opposite' that our research is oriented in terms of exploring the impact of MLDPs and the relationship between participants and the employing organization with an emphasis on disengagement. Our research question then is how do MLDPs generate the potential for disengagement between employees and their organizations?

The article is structured into five parts. First, we examine critiques regarding the shadow side of MLDPs; the unintended consequences such as participant disengagement with their home organization. Through analogous framing of an MLDP as an 'identity work space' we next explore how participation in a program might enable enhanced agency within the home organization with potentially consequential leader disengagement and distancing from the home organization. Third, we provide the detail about the specific program and the empirical setting. Fourth, we outline the methodology employed. Fifth, we present four elements that appear significant to understanding the relationship between an MLDP and the manifestation of participant disengagement with their home organization. Lastly, we provide a critical discussion regarding the shadow side of MLDPs and the phenomenon of participant disengagement with their home organization. The presence of such a 
phenomenon has significant implications to the leadership development field. We explore the same and offer suggestions for future research.

\section{The multifaceted consequences of management and leadership development}

\section{programs}

Management and leadership development programs (MLDPs) generally have the broad aim to 'enhanc[e] the capacity of organizations and the people within them to better achieve their purpose' (Bolden, 2016, p. 117). The majority of programs, as well as scholarly articles on MLDPs, take what Mabey (2013) calls a functionalistic approach to such development, focusing on how to build leadership capacity that maximizes organizational productivity; that is, producing 'changes in attitudes, behaviour, skills, status, or level of functioning' (Russon and Reinielt, 2004, p. 105). The functional perspective typically assumes that such changes and development of individual competencies easily translate into organizational effectiveness (Avolio et al, 2010). This orientation reflects the dominant unitarist human resource development perspective (Grugulis, 2017) where organizational members support the overarching organizational goals and members serve organizational needs. Development programs implicitly draw on this assumption that the purpose is to generate 'better' members equipped to help in the advancement of organizational goals and needs (Bolden, 2016; Mabey, 2013).

The range of expected individual changes towards becoming 'better' members goes beyond technical skills to include attitudes, beliefs, and identities of the managers. From a functionalistic perspective, MLDPs seek to enable the development of an 'enhanced sense of self' (Hay and Hodgkinson, 2008, p 30) or a stronger sense of individual agency, through self-narratives that offer a 'space of action' (Carroll and Levy, 2010, p 212). Further, assumptions behind such development is typically unitary, where the process seeks to generate similar outcomes for all participants, although to different degrees (Avolio et al, 2010). This perspective offers little space to consider 
that there may be fundamental variation of experiences and learning, resulting in pluralist outcomes and consequences.

Tourish, Craig and Amernic (2010) gave voice to the paradoxical nature regarding the agency issue of leadership development. Through examining the objectives and curriculum of a number of prominent business schools' modules on leadership development they explored the prominent discourse of developing individuals to become leaders that would be able to transform organizations. The MLDPs were seeking to generate messiah (Western 2019), heroic (Ford and Harding, 2007; Sinclair, 2009) and grandiose (Hay, 2014) leadership discourses. While the intended outcome of such discourses would be unitarist - all working for the same purpose, the good of the organization - the enhancement of individual agency implies the paradoxical pursuance of pluralist self-interest.

There is much distance between the unitarist intended outcomes and the complex pluralistic context of organizations (Bolden, 2016). While intended outcomes surely are fitted to some participants, others are bound to find themselves in more complex situations. A range of sources bear witness to a widespread disappointment with the actual impact of MLDPs (for instance, Gurdjian et al, 2014; Bolden, 2016), and that such programs to an unanticipated degree fail to secure and develop the 'better' members into the desired talent (Fernandz-Araoz, 2017). The simplistic assumption of direct skill and behaviour transfer is inherent in the typical functionalistic and unitarist MLDP perspective (Mabey, 2013). The organizational context to receive such transfer is a delicate ecosystem of dominant unitarist ideals and discourses alongside shadow pluralist realities of agents interests and conflicts, tensions and anxieties, and ambitions and disappointments. So into this ecosystem participants return from programs that encourage 'overcontrol [and] the unleashing of self-centred leader behaviours' (Tourish et al, 2010: S56) through an enhanced sense of agency. However, viewing organizations through the pluralist lens, difference and dissent are a natural part of working life. Consequently, if a program generates a greater sense of individual agency, along with an enhanced expectation of the importance of 
leadership (for the unitarist quest) and offer a better way of leading, then we suggest there is a very real possibility of disrupting the organizational ecosystem and the manifestation of resistance around them. Indeed, Wiggins and Smallwood (2018) highlighted that an MLDP with an overt individualistic (agency) focus might lead to a de-coupling of individuals from the organization. Rather than MLDPs generating 'better' leaders, the outcome could readily become perceived as disruptive, awkward, with the consequent outcome of disengaged leaders.

\section{MLDPs as a form of identity work spaces}

We have established how an MLDP can become a context to frame narratives of the self shaped by the ideas, understandings and expectations forged in the program. These notions of change in the individual are comparable to ideas of identity as a self-narrative (Carroll and Levy, 2010; Collinson, 2003; and Shaw, 2010); and also echo the regulative function of identity work (Alvesson and Willmott, 2002; Mallet and Wapshott, 2012; Watson, 2008; as well as the aspirational sense of a desired identity in Coupland and Brown, 2010). Finally, there is also much connection to the ideas of Brown (2015) and Watson (2008) who give emphasis to identity work as more than internal to the individual, but to also include intersubjective alignment with the social environment - most similar to an MLPD as a form of community of practice (Smith, Kempster and Wenger, 2018).

Linked to the dynamic in MLDPs towards self-discovery shaped by ideas of desirable leadership qualities (Ford and Harding, 2011) a program can catalyze a participant to scrutinize their organizations in new ways. Due to organizational plurality and complexity, such a process might have a range of different outcomes. For some, it might lead to stronger appreciation of their organizations, while others might be triggered to question how they relate to, and fit within, an organization in terms of the practices and identities prevalent therein. Program participation can enable a participant to reflexively see anew the organizational leadership practices, and through a sense of enhanced agency, resist such practices. Often the intention of MLDPs is to catalyze change to practices and such enhanced agency can achieve this desired goal. However, and drawing again on the notion of an MLDP as an identity work space, Petriglieri and Petriglieri (2010) suggest that 
an MLDP can be the cause of stimulating reflection with regard to challenging rather than developing alignment of a participant with the home organization. This may be of considerable impact if there is a sharp contrast between the home organization and practices contained therein, and the desirable (and perhaps seductive) ideas a manager is exposed to in an MDLP (Carroll, Levy and Richmond 2008; Elsbach and Bhattacharya, 2001). Within an MLDP, as a surrogate identity work space, participant reflexivity may 'prompt feelings of confusion, contradiction and self-doubt, which in turn tend to lead to examination of the self' (Brown, 2015: 25). In essence an MLDP can enable abandoning of an identity in favor of a suggested aspirational identity (Petriglieri, 2011: 648) offered up in the use of desirable leadership discourses (Ford and Harding, 2011; Shaw, 2010; Sveningsson and Larsson, 2006). In this way distancing (Michela and Vena, 2012) may become manifest as a consequence. Fried et al. (1996) found psychological distancing (called withdrawal in their study) to be antecedent to intention to leave. Emotional distancing thus becomes part of selfreappraisal to allow for movement toward an aspirational sense of self (Thornborrow and Brown, 2009). Rather than necessarily developing the individual for the home organization, for some participants the dynamic of the MLDP context and the program pedagogy may do the converse engender dissatisfaction and disengagement.

Building on Michela and Vena (2012), in which distancing occurs in relation to new situations, we are thus interested in how MLDPs as a situation, analogous to an identity work space (Hay, 2014; Petriglieri and Petriglieri, 2010; Warhurst, 2011), might influence a participant's relationship to the home organization, with particular attention to the use of distancing and disengagement.

This reappraisal of oneself in a leader or manager role, is fundamentally an emotional process (Winkler, 2018). Petriglieri and Petriglieri (2010) emphasize (in a positive affirming manner) how working through difficult emotions is an important part of establishing a new selfunderstanding. The everyday frustrations, tensions, stresses and anxieties of practicing managers can in this way become the curriculum within the MLDP. Iles and Preece (2006) describe how 
managers valued sharing doubts and insecurities from the home organization in the program, since the managers felt 'unable or reluctant to articulate this uncertainty to anyone in their own companies' (p. 329). The LPD might thus emphasize and amplify the experience of challenges in everyday work.

In essence, we wish to emphasize that MLDPs then can generate processes of destabilization of participants, just as well as the intended processes of stabilization. Viewing MDLPs as a pluralist dynamic that stimulates a range of responses, our focus here is primarily on the destabilizing outcomes. Viewing a program as analogous to an identity work space offers insight to the emergence of potential destabilization. The MLDP can become a dynamic to help 'help sooth their distress' (Petriglieri and Petriglieri, 2010: 46), and support sense making, elaboration, experimentation and consolidating into the new self; a new self positioned with expectations that may not be realizable in the home organization. The emotions of potential disappointment, disinterest and disengagement with the home organization may thus become manifest. Such disappointment may be extended through the sentient (and perhaps seductively beguiling) MLDP as a place of emotive release through emotional discourses (Winkler, 2018). The release occurring as a consequence of emotional suppression within the home organization (Fineman and Sturdy, 1999) from 'dominant discourses prevent[ing] the open exploration of emotion' (Hay, 2014: 534) regarding workplace challenges.

In summary we suggest two things: first, and following Gagnon and Collinson (2014), Carroll and Levy (2010), and Petrigileri and Petrigileri (2010), that MLDPs might be a significant context for self-reappraisal; and secondly, that such self-reappraisal within the program might include not only increased engagement with the organizational challenges, but in some cases also leader disengagement with the organization. Drawn from these two points our research question for this study is thus: How do MLDPs generate the potential for disengagement between employees and their organizations? We utilize an interview-based case study of an open MLDP in Sweden to 
explore the impact on participants in their subsequent encounters with everyday management and leadership challenges.

\section{The Management and Leadership Development Program - 'LEADING'}

The MLDP called 'LEADING' that we studied was initiated by a research trust associated with a mutual insurance company in Sweden, with the mission of improving working life conditions through dissemination of research findings and evidence-based knowledge. To this end, the fund sponsored, and continues to sponsor, development projects within relevant areas. The MLDP in focus here was one such project for cultivating "sustainable managers." The project was led by a steering committee including representatives from a public employer organization (SKL) and one employer organization from the private sector (ALMEGA), as well as representatives from the country's largest professional association for managers (Ledarna). The steering committee made all the major decisions in relation to the project, including determining the overall focus and design of the program, contracting a provider of the program (a well-known consultancy firm), and contracting a research team from a university for an evaluation study (first and second authors of this paper).

The rationale behind the program was an expected increase in the demand for managers in all sectors of society (due to demographic factors), and increasing dissatisfaction and distress among junior managers. The object of the program was therefore '...to create conditions for a healthy leadership role and thus make it possible to exercise leadership that contributes to higher organizational performance' (Bliwa Stiftelsen, n.d., translation by the authors). In the same text, a sustainable manager was defined as somebody who is '...willing and able to pursue a managerial career in a longer perspective' (Bliwa Stiftelsen)

Based on previous projects and a brief literature review, the project steering committee decided that the management program was to be built around Antonovsky's (1987) Sense of Coherence (SOC) - a concept that has been used extensively in research concerning health, health 
promotion, medicine and social work (Antonovsky, 1987). The program consisted of five seminars, each lasting 2-3 days, in total 12 days (Kontura International 2009; see also [author details withheld for review purposes]). Seminar content included: 1. Prerequisites for leadership; 2. My own leadership; 3. Leading change; 4. Similarities and diversity; and 5. The important balance (work-life balance). The seminars were spread over almost one year, with one seminar approximately every second month.

The program was based on a particular understanding of what a manager is. This was explicated in 7 principles for managerial work, namely: Purpose - to make clear why the organization exists; culture - to monitor important values and cultural messages"; the contract

- establish mutual obligations of employer and employee that cover all aspects of the job; linking for managers to act as linking pins between their co-workers and the management teams; energy to engender in coworkers a sense of meaning, pride and motivation; delegation - for managers to help co-workers solve problems through coaching and delegation; and interaction - to involve all coworkers in moving the organization forward. Drawn together the principles give emphasis to valuing clear hierarchical relationships, and preferably working in a well-structured bureaucracy.

In the program, these principles for managerial work were put to use in a number of ways. The participants were given various tasks between seminars, such as to get feedback on themselves from their superior manager, to conduct small 360-degree feedback surveys, or to diagnose their immediate team culture. During the seminars, the results of these tasks were discussed and held up against the program principles for managerial work. Problems and frustrations were thus made sense of in terms of deviances from these principles. Further, through extensive reflection and dialogue sessions, the participants were encouraged and expected to share and explore their workbased practices for these to be challenged, and potentially re-constructed.

\section{$\underline{\text { Participants }}$}

The program was open to participants from any organization, who had held a managerial position for a few years at most. Because the program was provided by the Bliwa Trust, it was offered free 
of charge. However, the participants and their organizations were required to cover travel and costs for residence during the retreats. The program attracted applications from public and private organizations, ranging from rather small organizations with fewer than 100 employees to large multinational corporations. In total, 90 participants were accepted, and 86 completed the program. Of the 86 program participants, 57 (66\%) were female, and 29 were male (34\%). The mean age was 41 years when the program started. The program participants had on average been in management positions for three years.

\section{Method}

Our research approach is based on interviews with participants of LEADING and of their supervising managers. The choice of interviews is based on our interest in the experiences of the subjects and the subjective meaning assigned to these experiences (Warren, 2002). We focus on the social worlds of our interview subjects (Miller and Glassner, 1997). Our position is social constructionist in the sense that the version of managerial challenges and organizational situations we work with is constructed by the participants in interaction with the interviewer and is based on an everyday understanding of their work. We further assume that this construction of their work context is real in the sense that it has real consequences (Hacking, 1999) in terms of how the managers collaboratively and individually relate to and at times try to change it.

Of the 86 participants in the program, 10 were chosen as interview subjects for this study. They were chosen as a stratified purposive sample, so as to represent all of the program cohorts, public as well as private, large and small organizations, and to have an even gender distribution. We also interviewed the supervising managers of these selected participants on two occasions. The participants were interviewed three times - at the start of, during, and after the program, producing 30 participant interviews. The repeated interviewing brought more depth (Johnson, 2002), in the sense of allowing a more thorough and personal exploration of central themes, that allowed us to follow the progress of the program better than had we only interviewed the subjects after the program. The supervising managers were interviewed at the start of the program and after it was 
finished (due to organizational changes and changes in roles, only 8 supervising managers participated in the final interview). In total, 47 interviews were conducted. The interviews were semi-structured in the sense of covering a number of themes - shown in Table 1.

Insert Table 1 about here

All interviews were transcribed. The analysis was primarily performed on the transcripts. However, we also returned at times to the audio file to check potential errors and to obtain a clearer sense of what was said. We utilized an empirically driven analytical strategy, in the sense of generating themes from the data (Strauss and Corbin, 1994). The first step was an open coding of the full material, focusing on leadership challenges, experiences and possible learning from the program and on how coding was related to participants' everyday work. Through iterative rounds of coding reviews, a set of 126 codes was finally defined. Second, through a more theoretically informed analytical strategy, the initial codes were arranged in hierarchies and broader themes, including at the highest level of abstraction such concepts as 'distancing' 'disengagement' and 'role reconstruction.' Links were made between the empirical material and the emerging theoretically informed framework in an abductive process (Mantere and Ketokivi, 2013) in which the coding of the empirical material was gradually refined and the theoretical framework was revised. To ensure high quality of the coding, both in the initial and later stages, a strategy of constant comparison (Strauss and Corbin, 1994) was employed. Codes were crosschecked across the material, similar codes critically examined, and cross tabulation employed to ensure that all material was examined similarly. The dual role of [first and second authors] generated contrasting views about codes and the later theoretically driven code hierarchy were discussed until a consensus emerged. Often, this process involved revising and refining the analysis.

\section{Findings}


The analysis of the interviews revealed that the MLDP facilitated two distinct and fundamentally different processes: either taking action to engage with their organization, developing and improving the managerial practices within the home organization; or disengaging with their home organization. In the following, we describe each in turn.

\section{Engaging to re-construct the managerial practices in the Home Organization}

Approximately half of the interviewed participants describe how they successfully pursued their newly acquired managerial and leadership knowledge and expectations, offered up by the MLDP, in their home organization. Discussions and reflection sessions in the program helped them to enact suggested managerial practices, and to re-negotiate and re-shape some of their immediate work environment, gaining validation and confirmation of what the participants may be able to enact. The first example of this is Charlotte seeking clarification of her task and her role as guided by the ideal model of a manager presented in the MLDP. Typically, this rethinking involved clarifying ones task, making demands in relation to ones superior, and saying no to tasks:

Charlotte: What do we need as managers? We need clarity. I need to know the boundaries of my role, what my position is, what I have authority over, I mean, things that were not clear before. I am in the process of getting these now.

Interviewer: In what ways?

Charlotte: Well, through discussions with my boss.

Or in the words of one of the supervising managers:

If I am unclear, she tells me so, she wants more clarity now.

The program triggered this process. For example, the principles for managerial work central to the MLDP explicitly stated that tasks needed to be clear, as in the notion of 'the contract', and through the notion of linking between hierarchical levels, which raised the question of what should be linked and how. The principles communicated in the program thus became a resource for working on developing managerial practices in the home organization. The program participants 
engaged in discussions with their supervising managers about which tasks to focus on, and by making new demands. As described by one supervising manager:

Manager: I feel that she and I work better together today, than what we did a year ago. She makes more demands on me, how I am to be, which is very good, it gives me the opportunity to provide her with what she needs. We get a much better cooperation. /.../

Interviewer: Right, so your experience is that she has become better at demanding things from you

Manager: and on the others, not just on me. She takes, if one can say like that, she occupies more space now, she occupies space.

Consistent with the principles of 'the contract' between supervising and subordinate manager, emphasized in the MLDP; the purpose of the organization; and delegation, the program participants were encouraged by the consultants in the MLDP to demand more resources from their supervising manager to establish a better congruence with the tasks they faced. This request could involve more time, more personnel, or various forms of monitoring systems and material resources. Clearly, as reflected by this supervising manager's positive view on being challenged, at times this process resulted in establishing alignment of the principles on the program with expectations of how managerial practices should be and could be enacted in the home organization. For example, on $L E A D I N G$ the participants were encouraged to actively say no to tasks and requests:

Interviewer: Has it been like this during the year; have you made your own decisions?

Charlotte: Definitely. But, I have raised demands in relation to [my boss].

Interviewer: In a way that you didnt do before?

Charlotte: Yes, right.

Interviewer: What kind of demands? 
Charlotte: I mean, I say no to her. When she tells me to do things, no, I wont make that, I say. That is not my responsibility.

Some of the supervising managers reported the same tendency to say no:

I think he is very good at maintaining boundaries, I don't know if it is a consequence of the program. I mean it was about sustainable management and to be a sustainable manager you must be able to draw a line, and I think Brad is very good at that. Stop, that is enough, I cannot make that, in that case I need to leave something else out.

The idea of clear responsibilities, highlighted in the MLDP as an important principle for managerial work, provided a rationale for saying no, even to ones supervising manager.

The form of change illustrated here consists not only in the individuals shifting their selfunderstanding, but also in active renegotiation of managerial practice expectations in the home organization. Empowered by subscription to a strengthened and clarified sense of ideal managerial practices, communicated to them in the MLDP, the managers engaged in various activities to enforce and seek confirmation of such practices, by seeking to influence their organizational environment. This resonates with what Petriglieri (2011) call a strategy of positive-distinctiveness; that is, to emphasize the practices in a positive way, including actively educating others about the value of managerial practices provided by the MLDP. Theirs are stories of engagement with their home organizations, and successful enactment of an enhanced sense of agency based on the MLDP principles for managerial work.

\section{Validating the programme principles by Disengaging with the Home Organization.}

For the other half of the interviewed participants, the application of the MLDP principles for managerial work surfaced as a process of distancing from, rather than engaging with, the home organization. This process comprises three aspects that will be elaborated below: diagnosing problems, emotional relief by attributing problems to the organization, and distancing from the organization. 
Diagnosing problems in the organization: The MLDP was helpful for many in thinking about their organizational context. Using the principles for managerial work from the MLDP as a norm for a well-functioning organization, participants could make sense of the challenges they encountered as problems with the organization. In the words of participant Ashley:

'Ive seen quite a bit of problems and deficits, based on what Ive learned, how an ideal organization should work. So, we have a rather long way to go. I feel even when Ive talked to my colleagues, Ive had the impress ion that everything just isnt right, in information channels and decision processes, and directives and policies, the way youd wish it should be.'

Aspects of the organization identified as being deficient included structure, roles, communication, and not least, leadership:

'What I can say is that I feel my eyes have been opened to other peoples shortcomings and their inabilities to say no. Perhaps I hadnt seen this before, or maybe its just clearer now, my view on how we conduct our daily work, what happens in some areas when a manager doesnt say no and delegates ... the insight into leadership, it has come there, it feels like if you, due to this course, [are] a bit ahead, see things in a different way.../.../ some of my biggest insights are into the problems and deficits of this organization and how important it is in a leadership role to be clear, to say no to all those parts.'

Not only was the organization found faulty, but the managerial role and practices are reevaluated and devalued. This type of critical view of the organization was also perceived by some of the supervising managers. As expressed by Irene's manager:

Manager: Yes, well, I might perhaps say that [participant I] has not been the most positive Interviewer: Right, so some people have been negatively oriented? Manager: Precisely, who maybe do not accept the organization and see themselves as being better than the rest, stuff like that. 
The many discussion and reflection sessions in the program, where the participants talked about their frustrations and work-challenges (similarly to what Iles and Preece,2006, describe), facilitated a reappraisal of the management practices of the home organization and indeed of the home organization as such. The principles for managerial work offered were consistently used as a normative model, treated as an ideal describing the 'utopian' (Ashley) organization, and offering an aspirational orientation to management practices. The principles were taken to imply that a 'wellfunctioning organization' (Irene) is critical for the exercise of management and leadership and by implication the home organization was not well-functioning. For Ashley and others the home organization was found wanting.

Emotional relief by attributing problems to the organization: For these participants, the gap between the ideas offered in the MLDP and the experienced organizational reality was further emotionally charged. The organization was blamed for not fitting the ideal (participants Ashley, Charlotte, David, Erica, Irene, and Ken). Identifying the problems and attributing them to the organization was often described as a strong emotional experience. As expressed by Charlotte:

'One thing we talked a lot about during the first seminar and that was an incredible aha for me, ... was these cornerstones [the principles for managerial work], which prerequisites are needed for me as a manager, for me to be able to do a good job. And already after this first seminar... ahh, it was a relief because Id thought that the things that were tough and difficult [were] about me and that I didnt have the knowledge and skills needed and ... that I didnt really understand ... Im not sure, I was a bit confused there. But, when I discovered that there [were] important tools that I just didnt have, a new worl d was opened to me. I could sort of place it outside of me, it wasnt about ME and that I was faltering, it was about the organization.'

The reflection sessions in the program appeared to offer an arena for release of previously experienced frustration, now amplified and possible to voice through the contrast with idealized ideas communicated in the program. Charlotte is giving voice to the instrumental role that the 
principles for management (the "cornerstones") played for this emotional relief.. LEADING provided 'a language to describe my frustrations' (Irene) or, in the words of Ashley:

'Much of what I felt was strange and heavy in the organization, I blamed myself for, and I don't do that anymore. This is one thing I have realized, that of course it is because of others (laughter). Now I can put things in perspective and I can offer an explanation or a solution. I couldn't do that before. I only felt it was confusing, but now I know why; it is because my boss does not give me a clear task, then of course my work becomes unstructured. I can't just formulate my own goals and targets for the group when my boss is not on board.'

Through reflections by the participants on the contrast between the idealized model of management practices, the burden of everyday frustrations were shifted from themselves and to the home or to a participant's manager. Occasionally, as for Ashley, this possibility was a new insight, whereas for others, it was rather a confirmation of previously held suspicions. In contrast to the participants engaging to re-construct their managerial practices (described in the first section), where reflections seemed to mobilize a readiness to improve their organizations, the emotional relief we describe here was more of an expression of letting go of such responsibilities.

Distancing from the organization: Hand in hand with the emotional relief of blaming the organization, allegiance to and emotional investment in the organization weakened reflecting a further step in this process of dis-engagement:

'I feel like I am not part of the organization, really, that's how it feels. It has probably felt that way the whole time, but it has become stronger during this year.'

While Ashley expressed a feeling of estrangement from the organization, Ken instead talked about not fitting in:

Interviewer: 'We talked earlier about how you received mixed feedback on your leadership, on the one hand negative feedback from your organization and on the other hand more positive from the leadership development program. What do you think about that?' 
Ken: 'To some extent I think that maybe I do not fit in here, my way of thinking might be completely different from what is considered as normal around here.'

Interviewer: 'How long have you felt like that? I presume you didn't think like that in the beginning?'

Ken: 'No, no, in the beginning I had a great time, it was fun, really fun. It was a challenge and I was full of energy. But then you get criticized for being asocial and not fitting in, that one has to change and so on. You have ... you did this the wrong way and so on. And that makes you think, maybe I should not be here.'

The discrepancy between his experiences at work and the norm presented in the program resulted in a destabilization of Ken in this organization and made Ken distance himself from the organization. Despite the fact that he had received some negative feedback from the organization, the experience of the feedback in the program shifted the burden of failure from him to reframe the issue as a misfit between him and his organization. . His distancing from the organization was reflected in his supervising manager's story:

'He is quite closed, quite blank as a person. At times, I have no idea of what he's thinking. You have to ask twice, at least. It's really like this: How do you feel? [with emphasis] I've learned that I need to really pull it out of him. Perhaps I do it all wrong, maybe I misinterpret him.'

Half of the interviewed participants actively considered leaving the organization. For David, it was a matter of realizing that he did not fit in and mentally made a choice:

'I believe I have found out what I need to function properly. I know what is important for me, or at least I think I know what is important. And I realize that I cannot have those things where I am now. I mean, can I have those things or should I do something different, those are my choices, and I believe that the easiest is if I do something different /.../ perhaps I 
simply do not fit in here. And either you hold on to it and suffer, or you try to do something about the situation.'

David's ambivalence is also reflected in his manager's description of him as somewhat slow and less engaged than what would be optimal:

'It's just that at times, it gets a little to theoretical, so to speak, like "maybe this way, or maybe that way", and then we sit there and say "but now let's do this, we need action now" and he says "ok" and then he goes away and fiddles with something.'

David's gradual distancing is reflected in his supervising manager's experience of a lack of shared engagement and connection. However, at this point in time he was not aware of David's intention to leave the organization. For Ashley, it was a matter of leaving in a clearly defined time frame. In her second interview, midway through the program, she explains how she has reached the decision to leave the organization through a quite surprising development process in the program:

Ashley: 'I have reached the conclusion that I don't want to remain here, and that is the fault of the program (laughter) well, I had some thoughts along those lines already when it started... but that it was going to be such a big step, I had no idea, I could never guess it should be such a process during this year, I really had no idea, there has happened a lot, on a personal level.'

Interviewer: 'And it sounds like you may be approaching some decisions?'

Ashley: 'Oh yes, I have decided, I won't stay here, I'm moving on after this fall.'

Distancing from the home organization could thus range from an emotional disconnection to actively trying to find employment in another organization. For the participants expressing this disengagement, the program provided a language and normative judgement to perceive the home organization and its management as failing. For some participants' the consequence of the heightened sense of confidence and agency was not to 'fix' the organization. Rather, we suggest such participants imagined the existence of other organizations in which the LEADING ideal was 
prevalent and such confidence and agency was driving them emotionally to search out such opportunities. The results show that disengagement happened in the program we studied. Not for all. For some the MLDP offered a space where the participants were able to examine management practices and engage with the organization to re-construct such practices, enabling more satisfying conditions and experiences of self-confidence.

Central to the functioning of the MLDP as a reflective space, was the emphasis of an idealized mode of managerial practices developed within the program. Exposure to these idealized management assumption can be seen to forcefully attempt to generate what Ford and Harding (2007) describe as an idealized leadership discourse to exert powerful influence on participant selfreflections. The self-reflections on home organizational weaknesses particular with regard to managerial practices did not reduce personal confidence and sense of self-efficacy. Rather the opposite was most prevalent for both those engaging to change the organization, as well as those disengaging with their home organization. Enhanced confidence was a prominent aspect measured as a highlighted success of the program - success heralded by the participants and of managers from the participating organizations. We thus have a paradox: a most successful program in terms of a unitary outcome of increased participant confidence and sense of agency that generates a pluralistic range of dissatisfactions with the home organizations that appear to manifest into two logics: to engage with changing the organization; or to disengage and emotionally or physically distance themselves from the organization.

\section{Discussion}

We think our study highlights a number of important elements. First of all, the study shows an interplay between agency and context. The program we have examined seeks to enhance agency expectations through outlining what management and leadership should be and what it should do in an organization and in essence saying 'this is your role and what you should do.' The MLDP is speaking to enhance agency expectations and impact, but it is also speaking about the context - how leadership and managerial practices should occur. In this way we are suggesting that MLDPs may 
have the dual effect of shaping agency expectations of themselves and at the same time shaping expectations of how the organization should be; setting up participants to return to the home organization with a potential heroic (Ford and Harding, 2007; Sinclair, 2009) or messiah discourse (Western, 2019) of the quest that needs to be pursued. Our data speaks of attempts by individuals to undertake such influence on the context and people they engage with, notably their line managers. When an individual evaluates the context as problematic, incapable of relying on their enhanced sense of agency to affect the necessary changes, we suggest individuals appear to commence a process of distancing and disengagement from the home organization and pursue an emotional quest for an imaginary host organization where their talents and ambitions can purposefully unite.

Second, we highlight the importance of emotions within MLDPs (Winkler, 2018). For some participants, enhanced agency advanced in the program enabled a highly emotional process, , and viewing afresh the managerial practices against the program ideal, unleashed experiences and expressions of frustration and disappointment. The new discourse from the program provided these participants with 'a language' (Irene - participant manager) for expressing their emotions. In this safe space, the emotions could be worked through (Petriglieri and Petriglieri, 2010), and attribution of the causes for frustrations to a failing organization brought emotional relief. As shown in our analysis, the opportunity for voicing and unleashing frustrations emerging against the home organization was central for the participants' sense of distancing and disengagement (similar to the findings of Iles and Preece, 2006). The MLDP as a holding environment brings a sense of relief, rather than bewilderment and 'floundering' (Nicholson and Carroll, 2013: 1237-38). In this way participants' agency is supported, encouraged and enhanced - a form of a liberating process as pushing back against the home organization.

Drawing the above elements together, we suggest that for some participants the program provoked a seductive orientation against the home organization. That is, against the perceived deficiencies of managerial practices of the context reinforced by the participants' sense of their own agency as 'better' leaders and desire to perform as 'better' leaders. To be clear we are not arguing 
that the organizational context in this data was blocking constructive transfer of learning. Instead, we wish to argue that the perception of the environment as failing, and an attribution of deficiencies to the context, were a consequence of the enhancement of agency. This outcome appeared to manifest for some to engage in changing management practices, and for others to disengage from the organization as a lost cause.

The attraction of this seductive process has at least two aspects. The first being subscription to an aspirational sense of the management and leadership role that promises competency and confidence. The second is a relief and separation from everyday frustrations and a sense of shortcomings, related to the managerial practices experienced in their everyday work. An important implication of this is to go beyond the seductive quality of the MLDP environment and processes (highlighted by Carroll and Levy, 2010; Ford and Harding, 2007; and Hay, 2014). We connect this seduction to a perception of enhanced agency to not only engage with changing the organization, but also seduced towards a unitarist ideal that may never be found: an imaginary unitarist organizational world where leaders are authentic, transformational and servant centred with enthusiastic followers willingly in pursuit of a unity of purpose.

We do not wish to suggest that enhanced agency and criticisms of home organizations, and for some the distancing that emerges, is a result of less well conducted MLDPs, but instead that it is an inherent dynamic of the well-designed and the well-executed program; a dynamic that is rarely acknowledged, but of much significance.

The distancing phenomenon is complex and paradoxical: on the one hand distancing occurs in MLDPs by the offering of a unitarist and functionalistic notion of the ideal form of leadership and management that does not exist in the home organization (and indeed may not exist elsewhere); whilst on the other hand the distancing is a result of pluralist tensions that emerge as a consequence of how an MLDP may enhance a participant's sense of agency. We suggest that the pluralist tensions present in the home organization clash with a participant's enhanced agency to pursue an idealized unitarist model. It is an ironic paradox that it is the enhancement of leadership agency that 
sponsoring organizations seek by encouraging leadership development that stimulates distancing. Further, we suggest that the distancing becomes self-sustaining. It is through distancing the managers preserve their enhanced agency, through seeking to avoid the frustrating and troublesome practical pluralist consequences. At the same time, the distancing facilitates subscription to the simplistic unitarist discourses for an ideal organization by a participant using the ideas from the MLDP to diagnose the pluralistic organization as failing and beyond repair.

Concerning the issue of individual agency our study casts individuals not as passive subjects in the MLDP - in contrast to Gagnon and Collinson (2014). Instead, the seductive offering of an idealized 'better' leader is taken up and utilized differently by the participants, depending on their individual work situations (as also described by Mallet and Wapshott, 2012). Their active construction of a 'space of action' (Carroll and Levy, 2010: 214) appears to be conducted through the tension between developing their self-narratives of both the idealized 'better' leader offered by the MLDP, and their ability to see the same developed within the home organization. Within this tension, the participants have a sense of liberating agency and expressed enhanced confidence and competency. In essence then, the study illustrates how discourses emanating from the MLDP (Tourish et al. 2010) constitutes new possibilities for individual agency, rather than stifling it. Our study thus aligns closely with the position taken by Nicholson and Carroll (2013: 1229), that 'one's sense of self [as leader] is not solely an individual choice' but that '[i]ndividuals are agentically performative' drawing on available resources, including discursive and interactional dynamics such as that afforded in an MLDP.

For us the observation of MLDPs as spaces for seductive enhancement of agency that for many lead to disengagement from the home organization pose most significant questions. At the outset of the article we outlined the substantial size of the leadership development industry, and the immense scale of investment. What would be the implications to this industry if MLDPs were seen to generate for many participants a sense of disengagement from their home organization? Enrolling on an MLDP as an exit route from an organization is a most plausible way for employees to create a 
positive and affirming sense of themselves as 'better' leaders that enables an emotional transition away from the organization. However we have not heard of any MLDP that openly advises that the pedagogy often generates disengagement. Perhaps designers of MLDPs are unaware of this dynamic when they are creating the program. Their enthusiasm and skill for successfully generating the seductive environment for such disengagement is at face value an earnest endeavor to help participants travel a journey of transformative learning (Smith and Kempster, 2019). Indeed this was the case for the MLDP we have studied. However, our analysis, along similar lines of Carroll and Nicholson (2013), suggest that the MLDPs need to be seen as places of seduction towards normative idealization, places that support agential push back against the realism of home organization expectations; and places that can unwittingly support participant resistance and disengagement.

For us this suggests a very real ethical requirement on those commissioned to design an MLDP for an organization to be conversant with the power implicit in their designs and the consequences it may generate for both participants and organizations. For example, how might sponsoring organizations respond to the suggestions emerging from our research that there is a strong likelihood that a significant proportion (possibly half) of participating employees may become distanced from the home organization? Would leadership development practitioners advise their clients? Could they do otherwise if the phenomenon we have illuminated in this article becomes part of leadership development discourse? How might the multi-billion pound / dollar leadership development industry adjust when client organizations become hesitant to funding MLDPs at the risk of losing key management talent. Or perhaps organizational clients may realize the opportunity to use the MLDP as a process to stimulate employees leaving? Perhaps many do this all already!

Finally, we question how an MLDP could be designed to limit distancing if at the heart of the design is to enhance agency. We offer two interrelated ideas: first, the discourse on ideal theories of leadership and management could be replaced with a discourse that ideal notions of leading, 
managing and organizing are fantasies, and Ramsey's (2011) notion of provocative theory may be an appropriate framing of decontextualized ideas; second we suggest that engaging participants in a critical discourse regarding the on-going tension of unitarist ideals and pluralist realties of organizational life may ground expectations on returning to the home organization. Taken together we suggest distancing may be lessened. However, taken together we question whether agency would be enhanced. As a consequence could such a design be sustainable? Why would organizations sponsor such programs? Thus we return to the paradox - the desire for enhanced agency for participants to become better managers and leaders to pursue the unitarist frame, whilst at the same time generating potential disengagement and distancing in addressing the pluralist reality.

\section{Limitations of the Research}

There are a number of limitations as a consequence of the research approach. First, the sample has limitations with respect to being a comprehensive representation of leader experiences from the program. Although we gave close attention to the sample participants' experiences a larger sample would extend the confidence of our conclusions in terms of representing a greater variety of organizational contexts including sector, size and diversity. Second, the arguments of MLDPs having an unintended consequence to impact on some participants with regard to disengagement research reflect the data from a single MLDP. We are not seeking to suggest the data is generalizable. Rather our intent is to bring attention to this area. Including more participants in a broader range of MLDPs would provide empirical testing of our preliminary observations. . Third, more research is also needed on knowledge acquisition in MLDPs in terms of the impact on confidence, enhanced agency and processes of disengagement. The pedagogy and selected curriculum, using the PMO, may have had impact that would not be reflected in alternative pedagogies and associated curriculum. Fourth, the research was singularly based on interviews where there is a reliance on the participants own accounts. Ethnographic studies of participants' practice and engagement in the employment context would provide insight into the challenges 
within their everyday work and the on-going identity construction, and how the manifestation of disengagement may be observed in terms of their relationships with colleagues. Finally, the aspect of gender has not been explored in this research. The sample of the interviewed participants, 6 were female, 4 male. The distribution is not atypical for lower level managers in Scandinavia. However it would be most interesting to pursue this theme - perhaps across programs and across cultures.

There is an absence of post MLDP research observations. Our research regarding identity reconstruction and potential disengagement and distancing from the home organization has greatly increased the need to understand this phenomenon.

\section{Conclusion}

Our study shows that the potential for MLDPs to engender disengagement between employees and their organizations can be understood as a process of enhanced agency, accomplished through the seductive process within the MLDP, where expectations of what a participant should seek to do in terms of managing and leading are contrasted with the shortcomings of the home organization. Further, our study suggests that distancing in turn works to enhance the participants' agency, as frustrations emanating from organizational complexities are attributed to a failing organization. Distancing builds on and in turn facilitates emotional relief through attribution of shortcomings to the organization.

We suggest our findings point to the need for MLDPs to consider most carefully the curriculum and pedagogy - moving away from idealization of leadership and organizational practices and normative models of leadership. Offerings of ideal and normative models of leadership are highly prevalent in leadership development, such as transformational leadership (Tourish et al, 2010) and authentic leadership development. These may come under much scrutiny. The consequence for the leadership development industry may become most significant. Organizational funding may move away from transformational learning pedagogies that embrace expectations of the sort of leader one should become, and toward a more prosaic focus on specific 
skills development anchored to the needs of the organization. For example, a focus on being better at particular aspects of leading, rather than becoming a different form of leader. If our findings become replicated through others studies, we submit that the leadership development industry is likely to experience considerable change, perhaps a major decline. Ironically both participants and organizations may become much less satisfied with such programs. The rave feedback of participants on the seductive transformational programs for being more confident leaders may disappear; and organizations become disappointed with the '[un]happy feedback forms.' Prosaic programs will be a hard sell; a hard sell to organizations and participants, and perhaps an equally hard sell to MLDP designers - where is the fun in developing a better speech, or active listening, or collective problem solving compared to developing people to find the leader within! So perhaps the tap will be turned off MLDPs and attention will turn to alternative forms of human resource development - perhaps even attention away from individuals and towards groups, organizing and responsibilities.

\section{References}

Alvesson M and Willmott H (2002) Identity regulation as organizational control: Producing the appropriate individual. Journal of Management Studies 39(5): 619-44.

Antonovsky A (1987) Unravelling the mystery of Health. How People Manage Stress and Stay Well. Jossey-Bass, San-Francisco.

Avolio, B J, Avey, J B, \& Quisenberry, D (2010) Estimating return on leadership development investment. The Leadership Quarterly, 21, 633-644.

Bolden, R (2016) Leadership, management and organizational development. In J. Gold, R. Thorpe, \& A. Mumford (Eds.), Gower handbook of leadership and management development (pp. 143-158). Routledge. 
Bliwa Stiftelsen (n.d.). http://www.bliwastiftelsen.se/Om-stiftelsen/Projekt/Hallbara-chefer/ (accessed 2 January 2012).

Brown AD (2015) Identities and identity work in organizations. International Journal of Management Reviews 17(1): 20-40.

Carroll B and Levy L (2008) Defaulting to management: Leadership defined by what it is not. Organization 15(1): 75-96.

Carroll B and Levy L (2010) Leadership development as identity construction. Management Communication Quarterly 24(2): 211-31.

Carroll, B, Levy, L, and Richmond, D (2008) Leadership practice: Challenging the competency paradigm. Leadership, 4(4), 363-379.

Carroll B and Nicholson H (2014) Resistance and struggle in leadership development. Human Relations 67(11): 1413-1436.

Coupland C and Brown AD (2012) Identities in action: Processes and outcomes. Scandinavian Journal of Management 28: 1-4.

Collinson DL (2003) Identities and insecurities: Selves at work. Organization 10(3): $527-$ 547.

Elsbach KD and Bhattacharya CB (2001) Defining who you are by what your e not: A study of organizational disidentification and the NRA. Organizational Science 12(4): 393-413.

Fernández-Aráoz, C, Roscoe, A, \& Aramaki, K (2017) Turning potential into success: The missing link in leadership development. Harvard Business Review, 95(6), 86-93.

Fineman S and Sturdy A (1999) The emotions of control: A qualitative study of environmental regulation. Human Relations 52(5): 631-63.

Ford J and Harding N (2007) Move over management we are all leaders now. Management Learning 38(5): 475-493. 
Ford J and Harding N (2011) The impossibility of the 'true self' of authentic leadership. Leadership 7(4): 463-479.

Fried Y, Tiegs R, Naughton TJ and Ashforth BE (1996) Managers' reactions to a corporate acquisition: A test of an integrative model. Journal of Organizational Behavior 17, 401-427.

Gagnon S (2008) Compelling identity: Selves and insecurity in global, corporate management development. Management Learning 39(4): 375-91.

Gagnon S and Collinson DL (2014) Rethinking global leadership development programs: The interrelated significance of power, context and identity. Organization Studies 35(5): 645-70.

Gilani P, Bolden R and Pye A (2014) The shadow side of leadership development. International Studying Leadership Conference, Copenhagen Business School, 13-15 $5^{\text {th }}$ December.

Grugulis, I. (2017) A very short, fairly interesting and reasonably cheap book about Human Resource Management. London: Sage

Gurdjian, P, Halbeisen, T, \& Lane, K (2014) Why leadership-development programs fail. McKinsey Quarterly, 1(1), 121-126.

Hacking I (1999) The Social Construction of What? Boston: Harvard University Press.

Hay A (2014) 'I don't know what I am doing!': Surfacing struggles of managerial identity work. Management Learning 45(5): 509-24.

Hay, A, \& Hodgkinson, M (2008) More Success than Meets the Eye-A Challenge to Critiques of the MBA: Possibilities for Critical Management Education? Management Learning, 39(1), 21-40. https://doi.org/10.1177/1350507607085170

Holmberg R, Larsson M and Bäckström M (2016) Developing leadership skills and resilience in turbulent times: A quasi-experimental evaluation study. Journal of Management Development 35(2): 154-169. DOI: 10.1108/JMD-09-2014-0093. 
Iles P and Preece D (2006) Developing leaders or developing leadership? The Academy of Chief Executives' programmes in the North East of England. Leadership 2(3): 317-340.

Johnson JM (2002) In-depth interviewing. In JF Gubrium and JA Holstein (Eds.) Handbook of Interview Research, (pp. 335-354). Thousand Oaks, CA: Sage.

Kontura International (2009) Hållbara Chefer - Nästa Generations Chefsutveckling Är Här. Rapport Från Kontura International [Sustainable Managers - The Next Generation Management Development is here. Report from Kontura International]. Bromma, Sweden.

Mabey, C (2013) Leadership Development in Organizations: Multiple Discourses and Diverse Practice. International Journal of Management Reviews, 15(4), 359-380.

Mallett O and Wapshott R (2012) Mediating ambiguity: Narrative identity and knowledge workers. Scandinavian Journal of Management 28: 16-2.

Mantere S. and Ketokivi M (2013) Reasoning in organization science. Academy of Management Review 38(1): 70-89.

McGurk, P. (2010) Outcomes of management and leadership development. Journal of Management Development 29 (5): 457-70.

Michela JL and Vena J (2012) A dependence-regulation account of psychological distancing in response to major organizational change. Journal of Change Management 12(1): 77-94.

Miller J and Glassner B (1997) The 'inside' and the 'outside': Finding realities in interviews. In D Silverman (Ed.) Qualitative Research (pp. 99-112). London: Sage.

Myatt M (2012) The 1 reason leadership development fails. New York: Forbes.

Nicholson H and Carroll B (2013) Identity undoing and power relations in leadership development. Human Relations 66(9): 1225-48.

Petriglieri JL (2011) Under threat: Responses to the consequences of threats to individuals' identities. Academy of Management Review 36(4): 641-62. 
Petriglieri G and Petriglieri JL (2010) Identity workspaces: The case of business schools. Academy of Management Learning and Education 9(1): 44-60.

Ramsey, C. (2011) Provocative theory and a scholarship of practice. Management Learning, 42(5): 469-483.

Russon, C, and Reinelt, C (2004) The results of an evaluation scan of 55 leadership development programs. Journal of Leadership \& Organizational Studies, 10(3), 104-107.

Sinclair A (2009) Seducing leadership: Stories of leadership development. Gender, Work \& Organization 16(2): 266-84.

Shaw J (2010) Papering the cracks with discourse: The narrative identity of the authentic leader. Leadership 6(1): 89-108.

Smith, S and Kempster, S (2019) In whose interest? Exploring care ethics within transformative learning. Management Learning, 50(3): doi.org/10.1177/1350507618822316.

Smith S, Kempster, S and Wenger, E. (2018) Developing a program community of practice for leadership development. Journal of Management Education, 43(1): doi.org/10.1177/1052562918812143

Strauss A and Corbin J (1994) Grounded Theory Methodology. An Overview. Thousand Oaks, CA: Sage.

Sveningsson S and Larsson M (2006) Fantasies of leadership: Identity work. Leadership 2(2): 203224.

Thornborrow T and Brown AD (2009) 'Being regimented: Aspiration, discipline and identity work in the British Parachute Regiment. Organization Studies 30: 355-376.

Tourish, D, Craig, R. and Amernic, J. (2010) Transformational leadership education and agency perspectives in business school pedagogy: A marriage of inconvenience? British Journal of Management, 21: S40-S59. 
Warhurst R (2011) Managers' practice and managers' learning as identity formation: Reassessing the MBA contribution. Management Learning 42(3): 261-78.

Warren CAB (2002) Qualitative interviewing. In JF Gubrium and JA Holstein (Eds.) Handbook of Interview Research (pp. 83-101). Thousand Oaks, CA: Sage.

Watson TJ (2008) Managing identity: Identity work, personal predicaments and structural circumstances. Organization 15: 121-143.

Western, S (2019) Leadership: A critical text. 3rd edition. London: SAGE.

Wiggins, L, \& Smallwood, J (2018) An OD approach to leadership development: questions and consequences. Journal of Management Development, 37(8), 613-623.

Winkler I (2018) Identity work and emotions: A review. International Journal of Management Reviews 20: 120-133.

Table 1: Themes of the Interview Guide

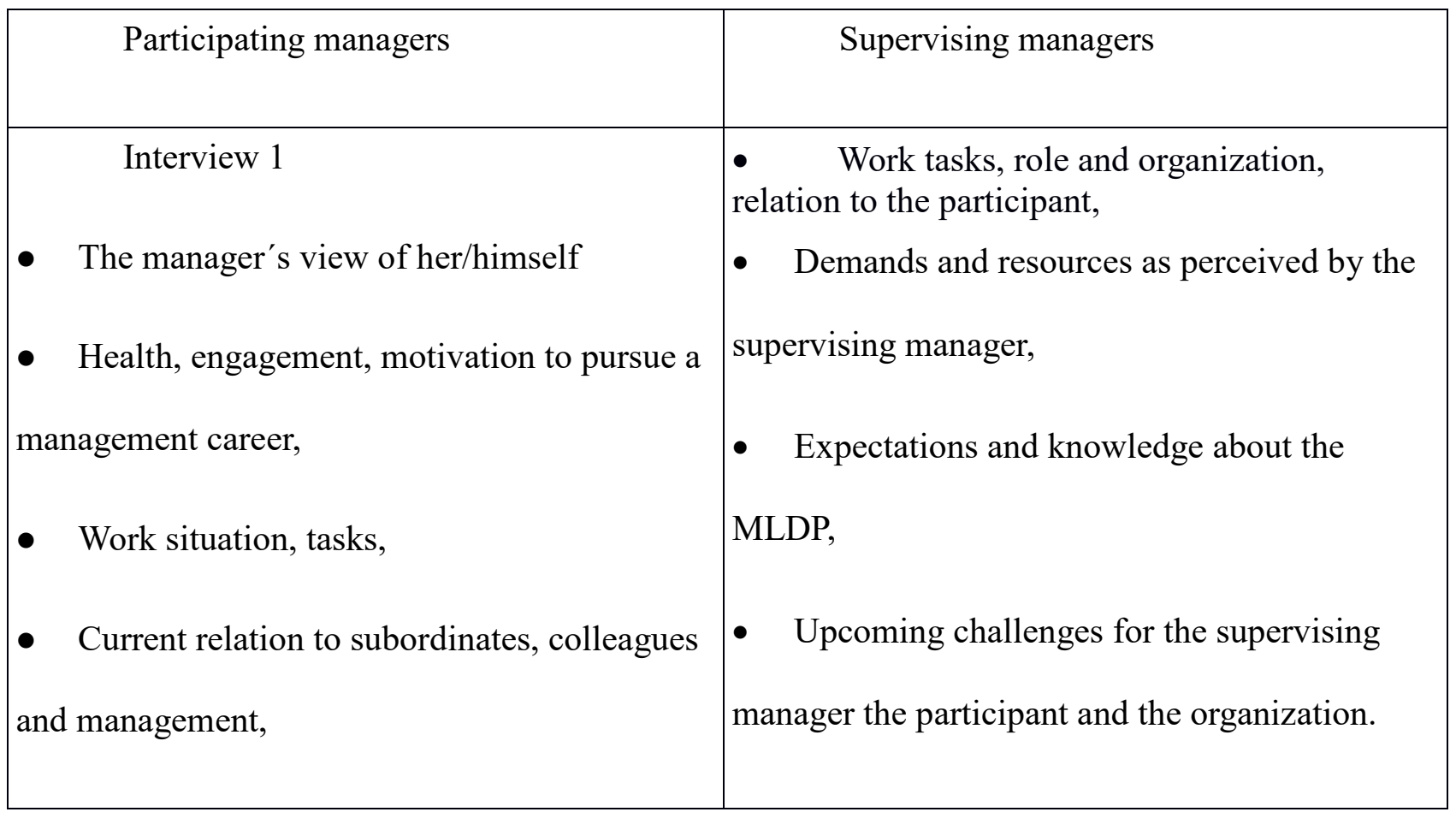


- Expectations on the MLDP.

Interview 2

- Experiences and thoughts about the program, possible connections between learning in the MLDP and the work situation,

- Health,

- Motivation,

- Relation to supervising manager and organization.

Interview 3

- Experiences and thoughts about the program, connections between learning in the MLDP and the work situation,

- Changes in work role, activities during the last year,

- Health,

- Engagement, motivation to pursue a management career,

- Current relation to subordinates, colleagues and management.

- Thoughts about one's future.
- Reconnect to interview 1 ,

- Changes in the participant,

- Changes in organizations, tasks and other aspects,

- Thoughts about the future. 